\title{
Monotonic and fracture behaviours of bolted connections with distinct bolt preloads and surface treatments
}

\author{
Vítor M.G. Gomes \\ Faculty of Engineering, University of Porto, Rua Dr. Roberto Frias, 4200-465 Porto, Portugal \\ vtgomes@fe.up.pt, bttps:/ / orcid.org/0000-0002-3982-6913
}

\author{
Mariana Rodrigues \\ INEGI, Rua Dr. Roberto Frias, 4200-465 Porto, Portugal \\ mfrodrigues@inegi.up.pt
}

José A.F.O. Correia, Miguel A.V. Figueiredo, Abílio M.P. de Jesus, António A. Fernandes

INEGI/ Faculty of Engineering, University of Porto, Rua Dr. Roberto Frias, 4200-465 Porto, Portugal

jacorreia@inegi.up.pt, bttps://orcid.org/0000-0002-4148-9426

mfiguei@fe.up.pt, bttps://orcid.org/0000-0002-6425-4339

ajesus@fe.up.pt, bttps://orcid.org/0000-0002-1059-715X

aaj@fe.up.pt, https://orcid.org/0000-0002-7146-9944

\begin{abstract}
This paper presents a research about the monotonic and failure behaviours of bolted joints made of thin plates of S350GD and S355MC steels grades applied for rack structures. A full factorial matrix of static monotonic tests was performed considering two joints configurations, two material thicknesses, three surface coatings and two preload levels. Slip tests were also performed according to the EN 1090-2 standard to evaluate joint slip factors for the three material surface conditions. Numerical simulations of static tests were also performed using $\mathrm{J} 2$ plasticity and compared with experimental data. From experimental results, it is verified that increasing thickness and preload results an increasing of failure loads and sliding loads, respectively. Slip tests revealed the lowest slip factors for the painted specimens, followed by uncoated specimens and the higher slip factor was verified for zinc-coated specimens. Regarding failure modes, it verified that the S355MC specimens with single connection fractured by shear, while the S350GD specimens fractured from splitting and shear. In addition, for specimens with multiple connections for both materials, the failure occurred in net cross-section. The FE results reproduced conveniently the ultimate loads as well as the failure modes, including the clamping and friction effects.
\end{abstract}

KEYwORDs. Rack Structures; Bolted Joints; Monotonic Behaviour; Friction; Numerical Simulation.

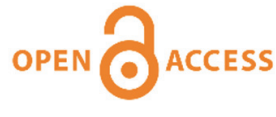

Citation: Gomes, V.M.G., Rodrigues, M. Correia, J.A.F.O., Figueiredo, M.A.V., Jesus, A.M.P., Fernandes, A.A. Monotonic and Fracture Behaviours of Bolted Connections with Distinct Bolt Preloads and Surface Treatments, Frattura ed Integrità Strutturale, 48 (2019) 304-317.

Received: 02.10 .2018

Accepted: 07.12.2018

Published: 01.04.2019

Copyright: (C) 2019 This is an open access article under the terms of the CC-BY 4.0, which permits unrestricted use, distribution, and reproduction in any medium, provided the original author and source are credited. 


\section{INTRODUCTION}

$\mathrm{O}$ ver the years the advances in investigation of manufacturing processes of cold-formed steels and the development of new technologies able to follow customers' requirements have allowed the used of cold-formed steel sections in various industry sectors. Due to the manufacturing process of cold-formed steel profiles, it is possible to obtain sections with mechanical characteristics optimized for the structural design with significant weight reduction. Cold-formed steel sections have been applied in energy (e.g. electricity) distribution industry, telecommunications transmission towers and automotive industry (e.g. frames for cars, buses, trains, etc). Moreover, coldformed steel sections are also used in rack structures applied in logistics warehouses where "storage and retrieval" (S/R) machines carry weighty goods at high speed over these structures in "7days-24 hours" economy. For this reason, loading conditions on this type of rack structures and their auxiliary components are not anymore quasi-static but dynamic, and cold-formed steel structural details may be subjected to load cycles in the order of 0.5 million/year. Currently, the EN 1993-1-3 standard only covers static design of structural solutions made of cold-formed thin-walled profiles. Because of this reason, FASTCOLD European project aims at providing rules for fatigue design of cold-formed steel members, with special focus on logistics industry. Cold-formed steel members are characterized by thin-walled sections and they are very often supplied with zinc coating. The connections between those members, mostly bolted connections, could be one of the critical locations that need to be conveniently addressed by research. Those connections are characterized by thin adjoining plates and different surface coatings could be used (e.g. zinc coating). Distinct preloads could be applied in practice since industrial practice, for example in rack structures, does not use controlled preloaded bolted joints. Instead, many times snug tight bolted joints are used. Fully threaded bolts (small shank lengths), associated to relative low preloads and low friction, leads to joint slipping and consequent inner hole surface indentation and damage. Therefore, research on bolted joints behaviour considering the previous specificities have been identified as a need to improve the existing rules for both static and fatigue behaviours. In this paper, the monotonic/static behaviours will be addressed.

Many researchers have been studying bolted connections in order to develop novel solutions or to improve existing solutions. In general, bolted joints provide many advantages in relation to other joining solutions, such as the good fatigue capacity, especially when using high-preloaded bolts, energy saving, usage of less skilled labour and adaptations. In addition to reasons mentioned, this type of connections is less dangerous for workers, so there is no risk of fire during erection works. However, bolted connections may have some disadvantages such as torque loss due excessive vibrations, which is a risk for structural integrity, the demanding positioning of the holes in the plates in the manufacturing processes and a greater control to selection the cross-section [1]. Although these shortcomings, bolted joints are a joining technique very common, but due its complex behaviour, they are still a subject of research around the world. General studies about the bolted connections strength, may include several particular research topics, such as the slip resistance of the bolted joints with the identification of respective slip factors for different surface conditions [2], the bearing strength at bolt holes with [3] and without [4] hole-bolt clearances for several connection geometries (end distance and bolt pitch). In addition to experimental tests, various authors have also been studied the behaviour of bolted joints by using numerical models. Chung [3] carried out a numerical model of bolted connections on cold-formed steel to evaluate the failure modes using lap shear tests. Silva [5] performed a numerical study with FEM using ANSYS, comparing the fatigue strength between riveted and bolted connections through experimental tests and numerical models. More recently, Rodrigues et al. [1] carried out the study on double shear bolted joints, investigating the influence of the friction coefficient and they present a discussion about the evolution of the linear-elastic stress concentration factors.

In this research work, the static monotonic behaviour of double-shear bolted butt joints with different clamping stresses (e.g. snug tight bolts, high preloaded bolts) are investigated, addressing particularly the failure modes. Besides static monotonic tests, slip factors are also evaluated by slip monotonic tests. Despite being a topic intensively investigated either experimentally or numerically $[6,7]$, this subject is revisited with a new testing campaign using relevant materials for rack structures, exploring the following aspects:

i) use of thin plates $(2-3 \mathrm{~mm})$, which are less common in other types of structures;

ii) effect of the preload levels;

iii) effect of different surface coatings;

iv) FE numerical modelling.

This work has been performed as a contribution for the FASTCOLD project and is considered as first step of the research preceding a fatigue characterization, under progress with similar bolted joints. 


\section{MATERIALS AND EXPERIMENTAL DETAILS}

$\mathrm{T}$ he purpose of this research is evaluating the mechanical behaviour of double-shear bolted joints, when they are loaded under tension, resulting on sliding between the cover/side plates and middle plates, which will result in posterior plastic failure by plate bearing or shearing.

\section{Basic materials description}

Two steel grades with very similar tensile and yield strengths, namely the S355MC and S350GD steels were investigated. The S355MC is a low-alloy mild steel, thermomechanically-rolled exhibiting outstanding formability; the S355MC is used for cold-forming, replacing conventional construction steel where high strength is paramount. In addition, S355MC is easily galvanized and welded. In other hand, S350GD is a zinc coated mild steel, which is obtained by hot-dip galvanization processes, providing it a good corrosion resistance. Tab.1 shows the chemical composition and the typical mechanical properties for S355MC and S350GD steels in accordance to the EN 10149 and EN 10346 standards, respectively. S350GD steel was also supplied with a painting coating, namely HEMPEL HEMPADUR $15553(60 \mu \mathrm{m})$ plus HEMPEL HEMPATEX ENAMEL $56360(60 \mu \mathrm{m})$. HEMPADUR 15553 is a two-component epoxy paint, which has good abrasion and impact resistance and well adherence properties. It is usually applied like primary paint over galvanized steel, aluminium, and stainless steel surfaces. HEMPADUR 15553 is also suitable when it is necessary to increase the roughening on surfaces. Moreover, HEMPADUR 15553 may be used as a low flame spread material. HEMPATEX ENAMEL 56360 is used as a finishing coating based on acrylic resin and non-chlorinated plasticizer. It is also resistant to salt water, splashes of aliphatic hydrocarbons and animal and vegetable oils. HEMPADUR 15553 and HEMPATEX ENAMEL 56360 are usually applied in moderately to severely corrosive environments.

\begin{tabular}{l|ccccccccc|ccc}
\hline & \multicolumn{8}{|c|}{ Chemical Composition (max \%) } & \multicolumn{4}{|c}{ Mechanical Properties } \\
& $\mathrm{C}$ & $\mathrm{Si}$ & $\mathrm{Mn}$ & $\mathrm{P}$ & $\mathrm{S}$ & $\mathrm{Al}$ & $\mathrm{Nb}$ & $\mathrm{Ti}$ & $\mathrm{Ti}$ & $\sigma_{Y} \min \mathrm{MPa}$ & $\sigma_{U} \mathrm{MPa}$ & $\varepsilon_{\mathrm{R}}$ \\
S355MC & 0.12 & 0.50 & 1.5 & 0.025 & 0.02 & 0.015 & 0.09 & 0.2 & 0.15 & $\geq 355$ & $430-550$ & $19 \%$ \\
S350GD & 0.20 & 0.60 & 1.70 & 0.10 & 0.045 & - & - & - & - & $\geq 350$ & 420 & $16 \%$ \\
\hline
\end{tabular}

Table 1: Maximum chemical composition (\%) and main mechanical properties of S355MC and S350GD steel grades, according to EN 10149 and EN 10346 standards ( $\sigma_{Y}$ min, minimum yield strength, $\sigma_{U}$, ultimate tensile strength and $\varepsilon_{R}$, total elongation).
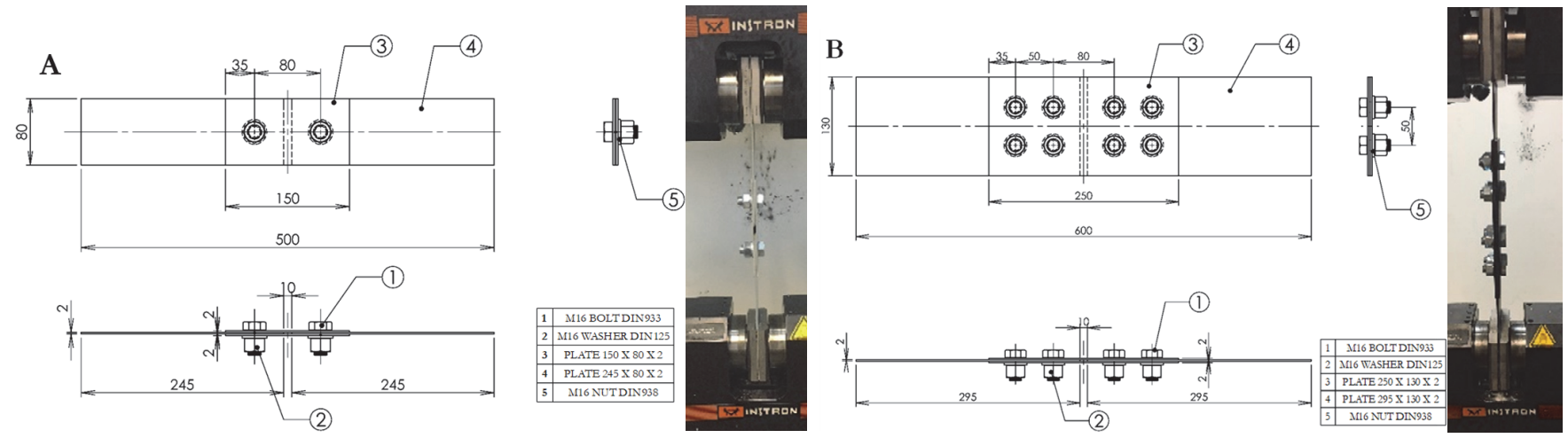

Figure 1: Geometry of the specimens used in static monotonic tests, with photo of the experimental setup: A) $1+1$ bolted joint; B) $4+4$ bolted joint.

\section{Experimental details description}

Monotonic static tests were performed on double-shear bolted butt joints to evaluate the influence of the connection geometry, bolt preloads, surface treatments, and the plate thickness effects in the mechanical strength and failure modes. Thus, several tests were performed with M16x30 bolts (DIN933, Grade 8.8), M16 washer (DIN 125) and M16 nuts (Grade 8). Two types of geometries ( $1+1$ and $4+4$ bolts), two preload levels $(70 \% F u$ e $25 \% \times 70 \% F u)$, three different surface finishing (uncoated, zinc coated and zinc coated plus painted), and two plate thickness ( 2 and $3 \mathrm{~mm}$ ) were considered, with three repetitions for each set, resulting into 72 monotonic static tests. The lowest preload level is 
proposed to represent non-preloaded bolted joints often used in rack structures and often called as snug-tight bolted joints. Fig. 1 shows the experimental setup used to perform the slip tests, its respective scheme and the dimensions of the tested specimens. In addition, the geometry data were listed in order to evaluate the influence of geometry and hole locations on failure modes. Tab. 2 shows the geometric parameters used and Fig. 2 illustrates them. $D_{\text {bole }}$ parameter corresponds to the plate hole diameters, $e_{1}$ the end distance, $e_{2}$ the edge distance and $p_{1}$ and $p_{2}$ the distances between centres of holes. Tab. 2 summarizes the series of specimens that were tested for two preloads and 3 repetitions $(12 \times 2 \times 3=72$ tests), where the first letter in specimen reference is related to the type of test (S-static), the second letter is the type of connection (S-single; M-multiple), the third letter is the type of coating (C-uncoated, Z-zinc coated and P-zinc coated plus painted); lastly, the numbers 2 or 3 in specimens reference are related to plate thickness in $\mathrm{mm}$.
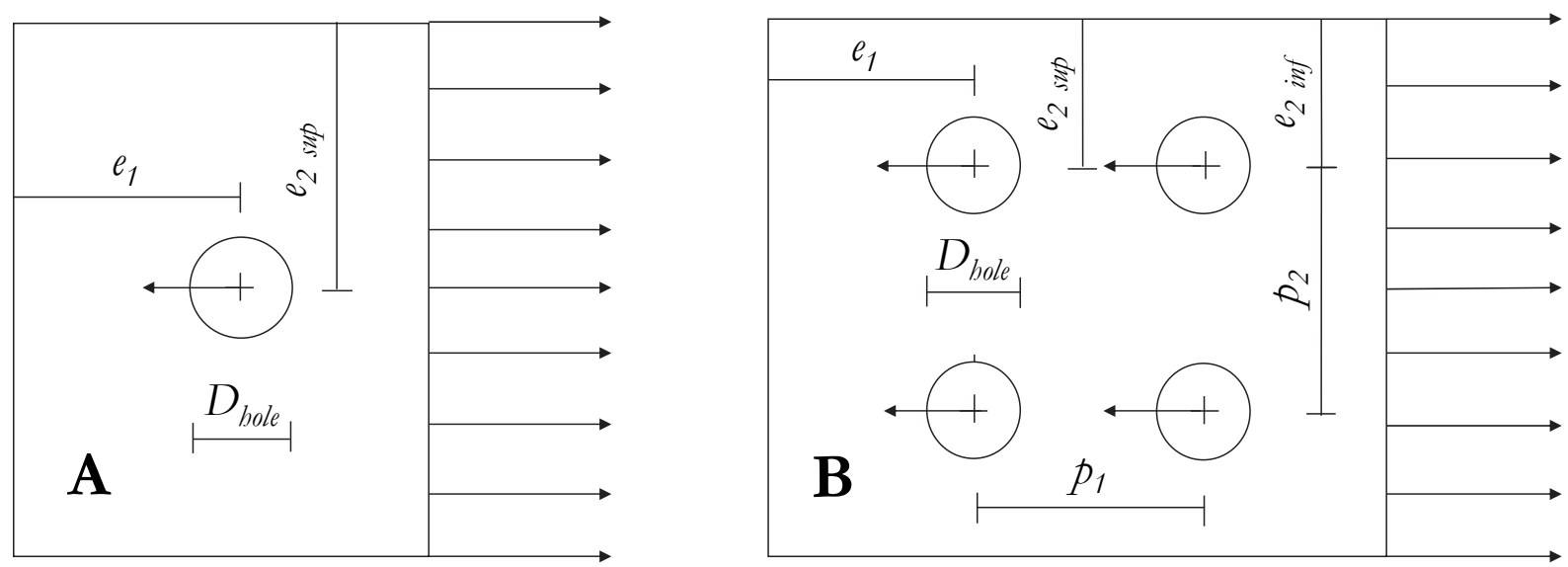

Figure 2: Definition of symbols used in characterization of bolted joints geometry: A) 1+1 bolted joint, B) 4+4 bolted joint.

\begin{tabular}{ccccccccc}
\hline Specimen & Thickness & Width & $D_{\text {bole }}$ & $e_{1}$ & $e_{2 \text { sup }}$ & $e_{2 i n f}$ & $p_{1}$ & $p_{2}$ \\
SSC2 & 2.00 & 80.00 & 18.03 & 35.01 & 40.00 & - & - & - \\
SSC3 & 2.89 & 80.06 & 17.97 & 34.96 & 40.04 & - & - & - \\
SSZ2 & 2.07 & 80.02 & 18.08 & 34.97 & 40.01 & - & - & - \\
SSZ3 & 3.03 & 80.08 & 18.05 & 34.64 & 40.04 & - & - & - \\
SSP2 & 2.50 & 80.30 & 17.65 & 34.94 & 40.15 & - & - & - \\
SSP3 & 3.32 & 80.13 & 17.60 & 34.50 & 40.06 & - & - & - \\
SMC2 & 2.06 & 130.01 & 17.90 & 34.94 & 40.06 & 40.12 & 50.01 & 50.07 \\
SMC3 & 3.09 & 129.98 & 17.97 & 34.97 & 40.09 & 40.09 & 50.02 & 50.04 \\
SMZ2 & 2.10 & 130.10 & 18.00 & 35.05 & 40.11 & 39.86 & 49.81 & 50.02 \\
SMZ3 & 3.09 & 130.23 & 17.95 & 35.08 & 40.25 & 40.01 & 49.99 & 50.08 \\
SMP2 & 2.40 & 130.32 & 17.65 & 35.02 & 40.18 & 40.15 & 49.82 & 49.95 \\
SMP3 & 3.31 & 130.40 & 17.57 & 34.86 & 40.31 & 40.22 & 49.70 & 49.95 \\
\hline
\end{tabular}

Table 2: Average dimensions ( $\mathrm{mm}$ ) of the test series (refer to Fig. 2 for nomenclature).

Besides the static tests, monotonic slip tests were also performed in accordance to the EN1090-2 standard [8]. The main goal of the slip tests was to evaluate the slip factors for three surface conditions mentioned before and the comparison of the obtained slip factors with static friction coefficients estimated by load-displacement curves obtained in monotonic static tests. The chosen parameters for the slip tests were: one preload level $(70 \%$ of bolt ultimate tensile resistance, Fu) and the three surface conditions already mentioned. A total of five repetitions for each type of surface finishing were performed, resulting in 15 slip tests. According to EN 1090-2 standard, the slip factors shall be evaluated for a sliding load correspondent to $0.15 \mathrm{~mm}$ measured with LVDTs. LVDTs with a stroke limit of $+/-5 \mathrm{~mm}$ were used to evaluate the relative displacement between the exterior and interior plates of the joints. Fig. 3 shows the experimental setup used to perform the slip tests, its respective scheme and the dimensions of the tested specimens. The experimental setup is composed by two blocks fixed on middle plates, which support four LVDTs (two LVDTs per block) and two stop plates 
fixed on cover plates. The slip factor values, $\mu_{\text {slip }}$, and the characteristic values, $\mu_{c}$, of the slip factors that accounts for $5 \%$ of occurrence probability, for a confidence interval of $75 \%$, are obtained by Eqns. (1) and (2):

$$
\begin{aligned}
& \mu_{\text {slip }}=\frac{\mathrm{F}_{\text {slip }}}{\mathrm{n}_{\text {bolt }} \times \mathrm{n}_{\text {shear planes }} \times \mathrm{F}_{\text {preload }}} \\
& \mu_{\mathrm{c}}=\mu_{\text {slip AVG }}-2.05 \times \mathrm{S}_{\mu}
\end{aligned}
$$

where the $F_{\text {slip }}$ is the load applied by machine test leading to slip, $n_{\text {bolt }}$ is the number of bolts, $n_{\text {shear planes }}$ is the number of shear planes (equal to 2), $\mathrm{F}_{\text {preload }}$ is the preload applied to the connection, $\mu_{\text {slip AVG }}$ is the average value and $S_{\mu}$ the standard deviation of the slip factors obtained for all the tests. In accordance to EN 1090-2 standard, preload force may be applied from different methods: torque method; combined method; HRC method or direct tension indicator method. In this study, torque method was considered, and the calibration of the preload level was performed. The torque clamping, $M_{\text {clamping }}$, is related with bolt nominal diameter $\mathrm{d}_{\text {bolt }}$, preload force and the calibration coefficient $\mathrm{C}$ as shown in Eqn. (3). Before performing the monotonic static and slip tests, the calibration of the preload level for two preloads was measured in order to obtain the calibration coefficient $\mathrm{C}$, using a dedicated load cell. The results confirmed a coefficient $\mathrm{C}$ equal to 0.2 .

In addition, tensile tests on samples of the steel grades used in the bolted joints were also performed to evaluate the differences on their mechanical behaviours. Tensile tests were performed with extensometer with gauge length equal to 50 $\mathrm{mm}$.

$\mathrm{M}_{\text {clamping }}=\mathrm{C} \times \mathrm{d}_{\text {bolt }} \times \mathrm{F}_{\text {preload }}$
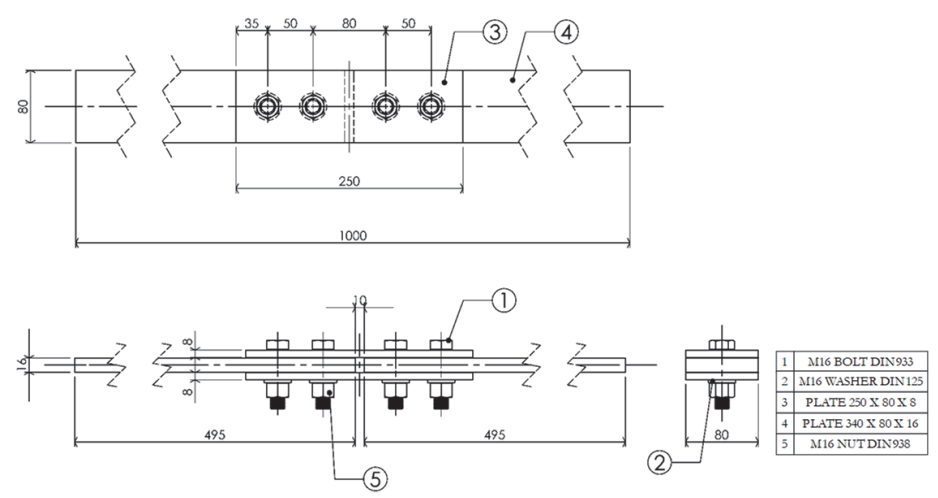

(3)
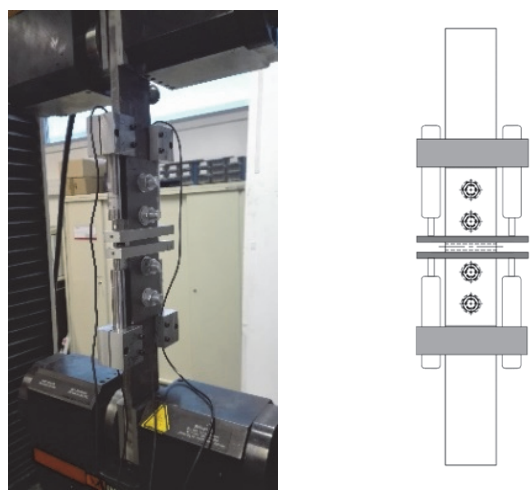

Figure 3: Geometry of the specimens for slip tests (left), test setup with LVDTs (centre) and scheme of the test setup (right) according EN1090 standard.

\section{NUMERICAL MODEL DESCRIPTION}

7 he finite element method was used to simulate the behaviour of the bolted connections. The main goal of this study was to determine the ultimate strength of the joints and then compare it with the average ultimate loads obtained by experimental tests. ANSYS 18.2 was used in this study and the components of the joints were modelled with hexahedral meshes composed by 20-noded solid elements (SOLID186). Contact surface elements (CONTA174 and TARGE170) composed by 8 nodes were also used to model the friction/contact behaviour between sliding faces of the plates and fastening. PRETS179 elements were inserted on middle of bolt body to apply the bolt pretension. The used numerical models are detailed below. 
Finite element modelling and parameters of the numerical models

The tested bolted connections (1+1 and $4+4$ bolts arrangements) were modelled. Good practice developed in a previous research by some of the authors was followed in this research [1]. Fig. $4 \mathrm{~A}$ and B show the FE models of the 1+1 and 4+4 connections, respectively. Due the physical and geometry symmetry, only $1 / 4$ numerical models were modelled, in order to reduce the computational costs of the simulations. This step was possible by the imposition of null displacements in the direction perpendicular to the planes of the symmetry ( $\mathrm{X}$ and $\mathrm{Y}$ axes). Regarding the mesh, a refinement of the finite element mesh was carried out in the proximity of the holes due to the expected higher stress concentration. In addition, full bolt geometry was considered, simplifying the bolt thread by a smooth cylindrical shape.

Contact pairs were used for all the contact possibilities that exist in the numerical model. Moreover, surface-to-surface contact option was used to impose the contact among Gauss points of the elements. Before modelling the contact pairs, it is necessary to identify the potential interactions between bodies. In summary, the following contact pairs were established: the contact between cover plates and middle plate, contact between bolt head and superior cover plate, contact between washer and inferior cover plate and the bolt shank and the holes of the three plates (cover and middle plates). In addition, it should be highlighted that all middle plate surfaces were meshed with CONTA174 elements and all fastening bolt contact surfaces were meshed by TARGE170. However, the hole contact surfaces of cover plates were meshed with CONTA174 elements, while the cover plate surfaces in contact with middle plate were meshed with TARGE170 elements. The contact between elements was considered flexible-flexible. Simulations were performed using Lagrange contact algorithm. This requires the definition of the contact stiffness and the interpenetration tolerance of the contact pairs to be applied in the normal direction to the contact surface. The contact stiffness was estimated by ANSYS, and it was based on elastic properties of the contact bodies which could be affected by a multiplicative factor, defined by the FTOLN parameter and is also a multiplicative factor to be applied to the thickness of the first layer of solid elements in contact for penetration tolerance. According to Silva [5], the amount of penetration between the contact surfaces depends on the value of the normal contact stiffness. For high stiffness values, there is a reduction in penetration, increasing the convergence difficulties of the contact algorithm. Low stiffness values can lead to high penetrations, thus producing less precise solutions. In this way, a sufficiently high stiffness is intended to reduce interpenetration between elements to acceptable values, ensuring convergence to the solution in a timely manner. According to the study carried out by Silva [1][5], the optimal values for these parameters are as follows: FKN (contact stiffness factor) equal to 0.1 and FTOLN (penetration tolerance factor) equal to 0.1 . These values were used in the present study. The initial penetration that may occur was ignored; anyway it is expected that does not exist any problems with this consideration because the finite elements are quadratic and can represent the real geometric hole.

The materials (S355MC and S350GD) were modelled with elastoplastic behaviour. It was adopted the Von Mises yield criterion, with isotropic hardening defined by multilinear law. The uniaxial engineering stress-strain curve was adopted according to experimental data obtained by tensile tests performed in this research. As regards the bolts behaviour, elastic behaviour was adopted taking into account that the ultimate load of bolt is greater than plate materials and the failure occurred in the plates. Tab. 3 summarizes the parameters used in constitutive law of the materials.

Regarding friction modelling, the Coulomb friction model was taken into account as provided by ANSYS 18.2 code. The friction law was based on Eqn. (4):

$$
\mu_{\mathrm{act}}=\mu_{\mathrm{dyn}} \times\left(1+(\text { Fact }-1) \times \mathrm{e}^{\left(-\mathrm{Dc} \times \mathrm{v}_{\text {rel }}\right)}\right)
$$

where $\mu_{\mathrm{act}}$ is the current friction coefficient, taking value equal to static friction coefficient, $\mu_{\text {stat }}$, before the sliding, $\mu_{\mathrm{dyn}}$ is the dynamic friction coefficient, Fact is the ratio between $\mu_{\text {stat }}$ and $\mu_{\text {dyn }}$, Dc is the exponent of decay, and $v_{\text {rel }}$ is the relative velocity between element faces. Due to lack of knowledge of some data like the exponent of decay, the Eqn. (4) was simplified, considering the exponent of decay equals to 0, becoming the Eqn. (5) in:

$$
\mu_{\mathrm{act}}=\mu_{\mathrm{dyn}} \times \text { Fact }
$$

The relationship between the static and dynamic friction coefficients, Fact, was estimated from experimental data. Thus, when the static friction load is reached, the sliding occurs. After this load level, the transition between static to dynamic friction coefficient is immediately, so the numerical sliding limit load can be incorrectly measured for situations where the Fact is relatively high. The static friction coefficient can be obtained from the first peak load on the experimental curve 
and the dynamic coefficient from the following load drop and respective load valley. For cases where the transition is not abrupt, Fact is very close to 1, verifying that differences between numerical and experimental sliding loads are lower.

A

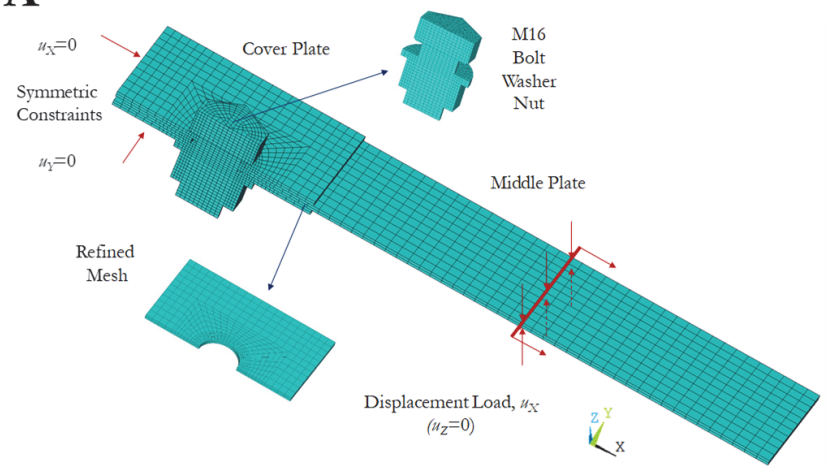

B

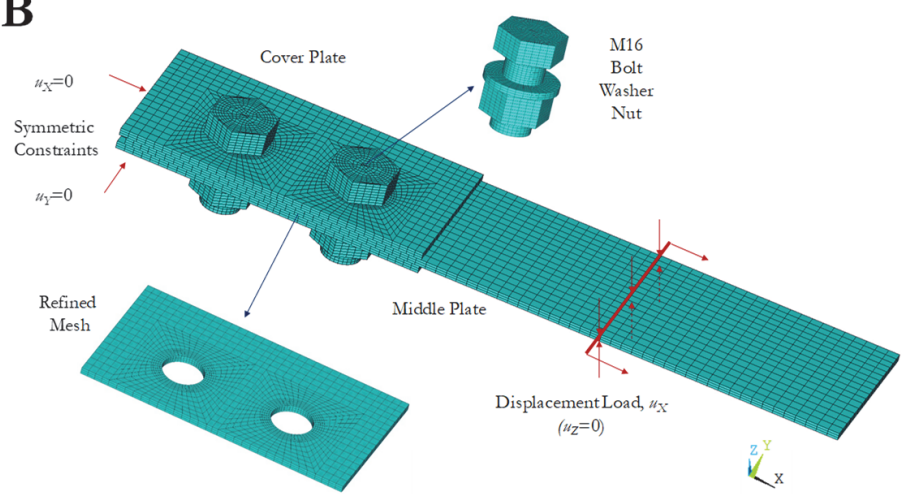

Figure 4: Typical FE mesh of two specimens, $1+1$ bolts, $2 \mathrm{~mm}$ thick (left) and $4+4$ bolts, $3 \mathrm{~mm}$ thick (right). Red arrows mean the boundary conditions (displacement constraints due to symmetry $\left(\mathrm{u}_{\mathrm{X}}=\mathrm{u}_{\mathrm{Y}}=0\right)$ and displacement loading). Blue arrows intend to show in more detail the mesh of some joint components.

\begin{tabular}{ccccc}
\hline & $E(\mathrm{MPa})$ & $v$ & $\sigma_{Y}(\mathrm{MPa})$ & $\sigma_{U}(\mathrm{MPa})$ \\
S355MC & $210 \mathrm{E} 3$ & 0.3 & 400 & 520 \\
S350GD & $210 \mathrm{E} 3$ & 0.3 & 425 & 500 \\
Fastening Bolt & $210 \mathrm{E} 3$ & 0.3 & - & - \\
\hline
\end{tabular}

Table 3: Mechanical properties used in finite element model built in ANSYS 18.2 (E, Young's modulus and $v$, Poisson's ratio).
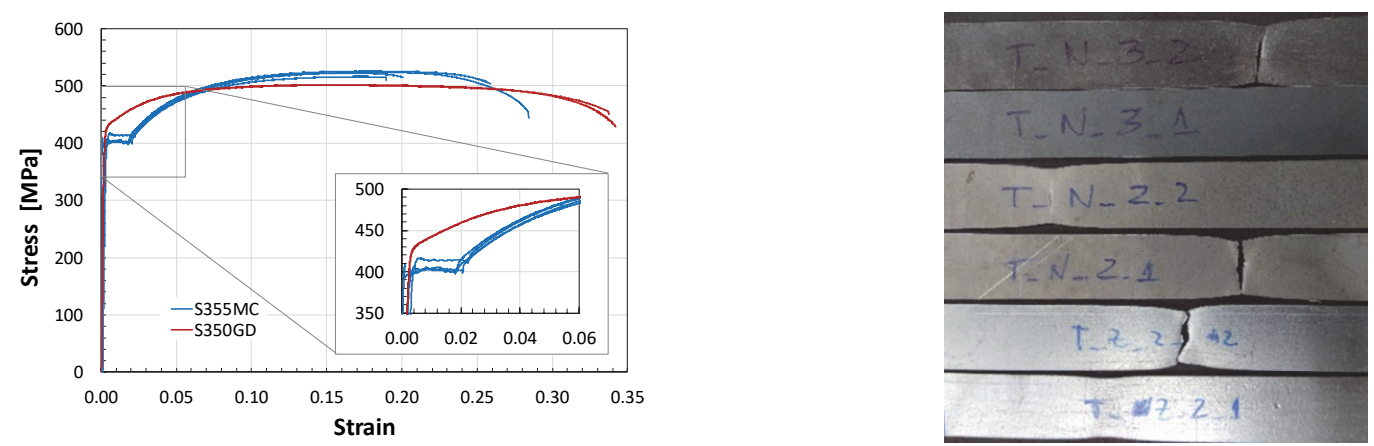

Figure 5: Conventional stress-strain curves of two steel grades under investigation (S355MC and S350GD). Detail shows the yield zone of the steel grades (left). Aspect of the specimens tested (first four (symbol N) are S355MC and last two (symbol Z) are S350GD).

\section{Preload application}

Many studies explain some ways to model the clamping stresses in bolted connections. According to Montgomery [9] and Kim et al. [10], one of the following processes can be used to model clamping stresses: thermal deformation, with constraint equations or by imposing initial deformations. According to the thermal deformation method, the pre-stress on bolt is generated from temperature variations and orthotropic thermal expansion coefficients to the bolt body [8, 9], while the initial deformation method allows imposing the initial displacement on bolt, becoming this method more direct than thermal deformation method. Although the mentioned methods presented their advantages, it is necessary to perform a previous calibration analysis of the parameters. In accordance to Zhang [11] there are two additional methods to apply the preload on bolts. The first one is using the pretension element method, which is a method where PRETS179 elements (provided by ANSYS) are applied directly on bolt sections previously defined. The preload force is imposed in first load step, and kept for the next load steps, reducing the work time. Another way to apply the preload is by the tightening method. In this method, the threads and helix angle geometries are considered, becoming the computation efficiency very 
low; however, computation results are more accurate and local contact stress can be obtained. Results by Zhang [11] showed that the pretension element method is enough and can reproduce good numerical results taken into account its simplicity. For these reasons, this method will be used to model the clamping torque on bolts.

\section{Displacements application}

The imposed displacement values are very important because these values should be chosen in order to cover the joint behaviour until ultimate loads are achieved. The adopted displacement values were about 17 and $12 \mathrm{~mm}$ for single and multiple connections, respectively. The displacements were defined in the longitudinal axis, X. Also displacements were applied in $\mathrm{Z}$ direction on the free nodes of the clamping grips of the testing machine, as signalized in red line/arrows in Fig. 4. The imposed displacements together with the symmetry boundary conditions impeded any rotation of the specimen ends as occurred in the gripping provided by the machine.

\section{RESULTS AND DISCUSSION}

$\mathrm{I}$ nitially and due a lack of knowledge about mechanical behaviour of the two steel grades, preliminary tensile tests were performed in order to obtain more information that will be very useful for correct modelling of the joints and to explain some differences between the two steel grades. Fig. 5 (left) illustrates uniaxial engineering stress-strain curves for S355MC (blue) and S350GD (red); Fig. 5 (right) shows the final aspect of the tested specimens. Regarding to the experimental curves, they show that the S350GD has some differences in comparison with S355MC steel. Firstly, S350GD has an ultimate strength lower than S355MC however the S350GD showed greater ductility. Zinc coated steel does not present yield plateau like S355MC. The yield plateau is a typical characteristic of the hot-rolled steels, while the transition from elastic to plastic behaviour without a perfectly defined point is characteristic of the cold-formed steels [12, 13]. As regards the failure modes of tensile specimens, Fig. 5 (right), both steels show a typical mild-steels failure behaviour with necking followed by final perpendicular to slightly inclined to loading direction cracking.

Regarding the slip tests, sliding forces $\left(\mathrm{F}_{\text {slip }}\right)$ measured between plates with LVDTs were used to compute the slip factor values $\left(\mu_{\text {slip }}\right)$. Slip factors for each test were calculated using Eqn. (1). In addition, the characteristic values of the slip factors were also calculated according to Eqn. (2), taken into account the average and standard deviation of the slip factors calculated previously. Tab. 4 shows the sliding forces, slip factors and their correspondent coefficient of variations, CoV, for the three tested surface treatments. Results showed that zinc and zinc plus paint coatings resulted in the greatest and the lowest slip factors, respectively. From Tab. 4 is also possible to verify that the coefficient of variations were relatively high.

\begin{tabular}{|c|c|c|c|c|c|}
\hline \multirow{2}{*}{ Steel Grade } & \multirow{2}{*}{ Surface Treatment } & \multirow{2}{*}{$\begin{array}{l}\text { Sliding Force } \\
F_{\text {slip } A V G}[\mathrm{kN}]\end{array}$} & \multicolumn{2}{|c|}{ Slip Factor } & \multirow{2}{*}{$\operatorname{CoV}[\%]$} \\
\hline & & & $\mu_{\text {slip } A V G}$ & $\mu_{c}$ & \\
\hline S355MC & Without coating & 97.06 & 0.28 & 0.16 & 21.65 \\
\hline S350GD & Zinc coating & 107.90 & 0.31 & 0.20 & 18.77 \\
\hline S350GD & Zinc plus paint coating & 47.28 & 0.14 & 0.09 & 15.56 \\
\hline
\end{tabular}

Table 4: Average sliding forces $\left(F_{s i p} A V G\right)$, average slip factors $\left(\mu_{s l i p} A V G\right)$, characteristic slip values $\left(\mu_{c}\right)$ and respective coefficient of variations ( $\mathrm{CoV}$ ) obtained from the slip tests, for the three investigated surface treatments.

Friction coefficients were also evaluated from static monotonic tests. Static friction coefficients were estimated from loaddisplacement (load-disp.) curves. The method consisted in detecting the load peak or the curve slope variation, the latter being useful for load-disp. curves with abrupt slope variation. In other cases, the slope variation was softer or for some cases some vibration occurred and therefore the correct detection of peak load was not possible. In these cases, the minimum values were considered to identify the starting of sliding. Tab. 5 shows the results and can be verified that the slip factor according the slip tests is very different when compared with average friction coefficients according to the static/monotonic tests. However, according to Picard [14] for steels without special treatment, the average slip coefficient is 0.33 for most of steels, being able to occur values around 0.23 . These slip factor values are characteristic of steels provided by clean mills. In addition, for surfaces as rolled, the slip factors could be 0.20, according to EN 1090-2 [8]. As regards the steel submitted to hot-dip galvanizing process (zinc coating), the average slip values from slip and static tests are within the interval from 0.08 to 0.36 [14], validating the approach assumed initially. The friction coefficient values 
obtained from static tests are lower than specimens without coating due the presence of soft zinc layer that tends to act like a lubricant. The high value of slip factor in zinc coated specimens may be caused by the surface treatment processes that the specimen was subjected before galvanizing process, and/or the effect of the decrease of the thickness that increases the coefficient of friction, which according to Picard [14] is the main reason for the variation of friction coefficient values. Lastly, specimens with zinc plus paint coating resulted in more similar values between static and slip tests.

\begin{tabular}{|c|c|c|c|c|c|c|}
\hline & & & & \multicolumn{3}{|c|}{ Surface Finish } \\
\hline & & & & $\begin{array}{l}\text { Without } \\
\text { Coating }\end{array}$ & $\begin{array}{l}\text { Zinc } \\
\text { coating }\end{array}$ & $\begin{array}{l}\text { Zinc plus } \\
\text { paint coating }\end{array}$ \\
\hline \multirow{2}{*}{ Monotonic/Slip Tests EN 1090} & \multirow{2}{*}{$\begin{array}{l}\text { Preloaded Bolts } \\
\quad(70 \% F u)\end{array}$} & \multirow{2}{*}{$\begin{array}{l}2+2 \\
\text { bolts }\end{array}$} & $\begin{array}{c}\text { Slip Factor } \\
\mu_{s l i p} A V G\end{array}$ & 0.28 & 0.31 & 0.14 \\
\hline & & & $\begin{array}{c}\text { Charact. Slip } \\
\mu_{c}\end{array}$ & 0.16 & 0.20 & 0.09 \\
\hline \multirow{8}{*}{ Monotonic /Static Tests } & \multirow{4}{*}{$\begin{array}{c}\text { Snug Tight } \\
\text { Bolts } \\
(25 \% \times 70 \% F u)\end{array}$} & \multirow{2}{*}{$\begin{array}{c}1+1 \\
\text { bolts }\end{array}$} & $2 \mathrm{~mm}$ & 0.18 & 0.09 & 0.06 \\
\hline & & & $3 \mathrm{~mm}$ & 0.22 & 0.10 & 0.09 \\
\hline & & \multirow{2}{*}{$\begin{array}{c}4+4 \\
\text { bolts }\end{array}$} & $2 \mathrm{~mm}$ & 0.23 & 0.11 & 0.13 \\
\hline & & & $3 \mathrm{~mm}$ & 0.14 & 0.11 & 0.14 \\
\hline & \multirow{4}{*}{$\begin{array}{l}\text { Preloaded Bolts } \\
\quad(70 \% F u)\end{array}$} & \multirow{2}{*}{$\begin{array}{c}1+1 \\
\text { bolts }\end{array}$} & $2 \mathrm{~mm}$ & 0.17 & 0.15 & 0.08 \\
\hline & & & $3 \mathrm{~mm}$ & 0.16 & 0.14 & 0.10 \\
\hline & & \multirow{3}{*}{$\begin{array}{c}4+4 \\
\text { bolts }\end{array}$} & $2 \mathrm{~mm}$ & 0.13 & 0.11 & 0.09 \\
\hline & & & $3 \mathrm{~mm}$ & 0.14 & 0.13 & 0.10 \\
\hline \multicolumn{2}{|c|}{ Average friction coefficient from static tests } & & & 0.17 & 0.12 & 0.10 \\
\hline
\end{tabular}

Table 5: Slip factors $\left(\mu_{\text {slip } A V G}\right)$ obtained from the slip and static/monotonic tests.

The load-displacement experimental results from the static monotonic tests are showed in Fig. 6. From Fig. 6 one verifies that the increase of thickness induces greater failure loads as expected, however the increasing of failure loads is greater on specimens with $4+4$ bolts than in specimens with $1+1$ bolts. The comparison of the geometries show a large difference in the maximum displacements due to the different failure modes verified. The $4+4$ bolted connections failed in the net cross-section of the first two holes, while the $1+1$ bolted connections presented shear fracture and shear with splitting fractures for S355MC and S350GD steel grades, respectively. Regarding the preload level applied on bolts, Fig. 6A shows that the preload level is the important factor to increase the sliding load, however it is also possible to see that the increase of preload has some influence on ultimate failure load (Fig. 6B). Fig. 6 also includes a comparison between experimental and numerical curves and there are some differences on initial behaviour corresponding to the sliding of joint. These differences are due to the complexity of the friction phenomenon and therefore a detailed analysis is necessary to characterize the friction behaviour correctly. From Fig. 6A, we may verify that S355MC specimens present a sticking/sliding effect as well as S350GD with zinc coating plus painting; specimens made of S350GD with zinc coating the sticking/sliding effect is not clear. This aspect is extremely important to the real representation of friction behaviour of the joint. However, it should also be highlighted that the associated errors for friction coefficient did not influence the final behaviour for lower bolt preload levels; but the friction coefficient may have a significant influence for higher bolt preload levels, if the thickness is small enough, like the specimens with $2 \mathrm{~mm}$ thickness. From Fig.6B we can verify that for specimens with $3 \mathrm{~mm}$ thickness, the failure load is greater for uncoated steel. However, for specimens with $2 \mathrm{~mm}$ thick plates, the failure load is greater for specimens with zinc coating. In addition, it verifies that the difference between ultimate loads of specimens with zinc plus paint coating and only zinc coating is very small, allowing to conclude that the paint do not influence the strength of the connections.

The numerical results were very satisfactory on predicting the ultimate loads, with a maximum error of $8.68 \%$ on specimen made of S350GD, with $2 \mathrm{~mm}$ thick plates and preloaded bolts. About experimental tests, the maximum deviation of results occurred for specimen S355MC (uncoated) with $3 \mathrm{~mm}$ thick plates and $1+1$ configuration and preloaded bolts. It is also possible to verify that the greatest $C o V$ was verified for specimens with preloaded bolts, reinforcing the idea that for higher preload values, the dispersion of results is greater. Tab. 6 compares the experimental and estimated failure loads where the maximum values of $\mathrm{CoV}$ and Error are in bold figures. 
A
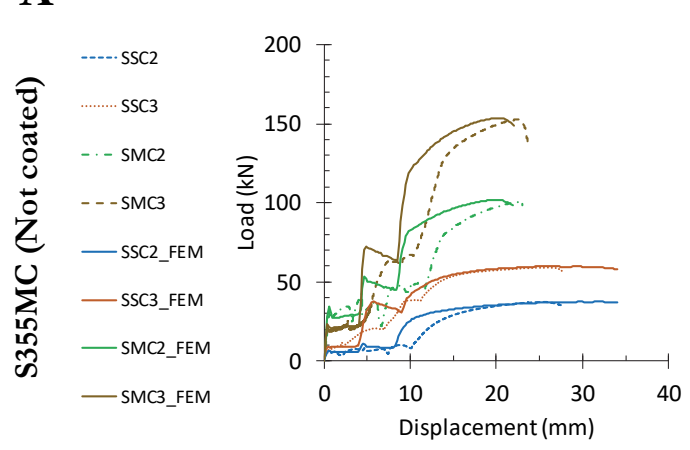

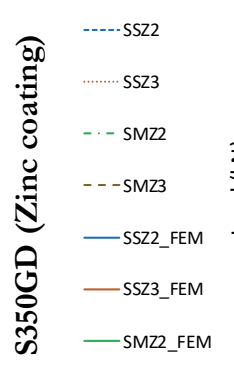

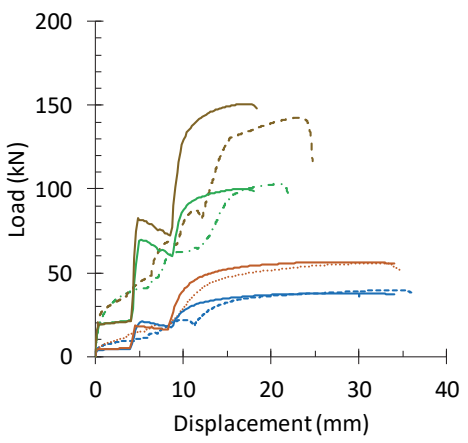

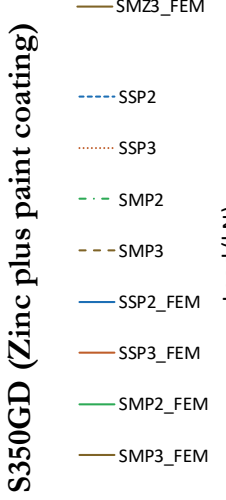

Preload $=140 \mathrm{MPa}$

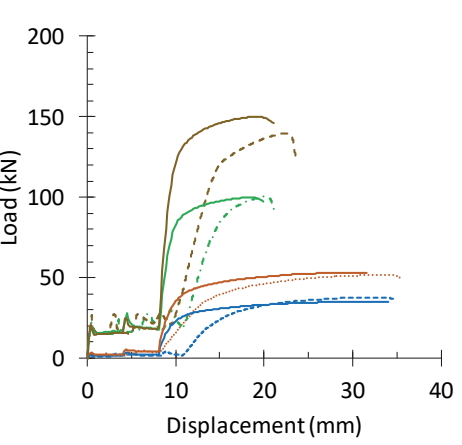

Preload $=560 \mathrm{MPa}$
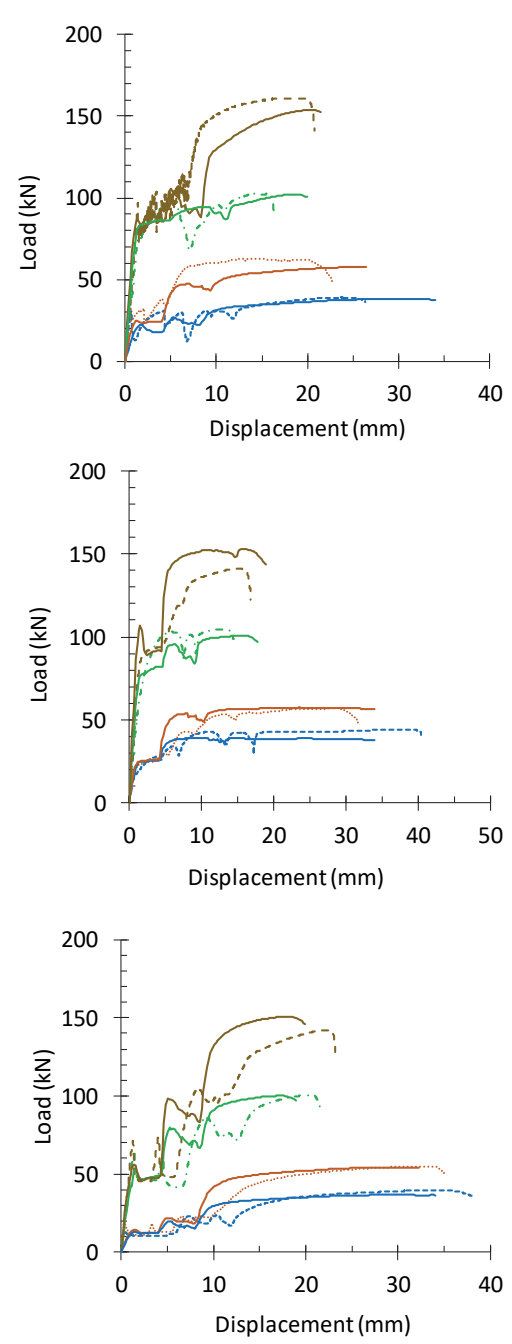

B
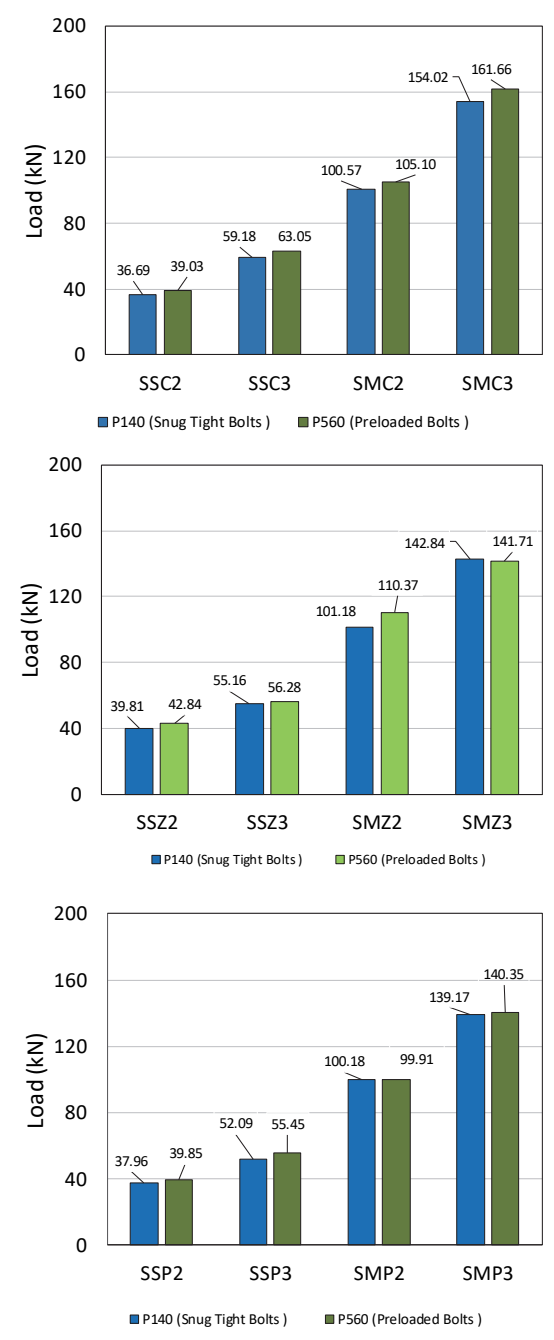

Figure 6: A) Experimental vs. numerical load-displacement curves; B) Failure loads obtained in the monotonic static tests for two preload levels $(25 \% \times 70 \% \mathrm{Fu}$ and $70 \% \mathrm{Fu}$, or 140 and $560 \mathrm{MPa}$, respectively).

A set of experimental and numerical load-displacement curves were chosen to explain in detail the friction and mechanical behaviour of bolted joints. Fig. 7 illustrates the multiple bolted joints behaviours made of S350GD steel with zinc coating plus painting until the moment that plate starts to yielding. These curves were chosen because they are representative of the behaviour of all studied specimens (single and multiple bolts for all preload ranges). Also there was a good agreement between the numerical and experimental curves. Initially, specimens were assembled in such a way to allow the maximum possible sliding (1). From (1), the load increases and the static friction coefficient prevails until (a). After (a), the friction coefficient decreases to the dynamic friction coefficient and consequently, the recorded load decreases, becoming almost constant until the contact between the middle plate and the bolt shank is established (2). Then the load increases again due to slippage resistance of fastening set until the applied load exceed the total friction load (b), inducing the movement of middle plate and fastening bolt until disappearing all gaps (3) and the load increases due to deformation of middle plate (4) until its failure. It is worth noting that the two load plateaus visible in Fig. 7 are similar to the ones observed by Rodrigues et al. [1]. The only difference is that in the current research two friction coefficients $\left(\mu_{\mathrm{stat}}\right.$ and $\left.\mu_{\mathrm{dyn}}\right)$ are used, which induces extra oscillations in the reaction loads [1]. Comparing the experimental and numerical curves, it is noted that there are differences between experimental and numerical friction behaviours. Firstly, there is a difference between instant the gaps disappeared. Theoretically, the gap is equal to $4 \mathrm{~mm}$ for each side of specimen, resulting on $8 \mathrm{~mm}$, but only after about $6 \mathrm{~mm}$ of experimental displacement there is again an increasing of load. This fact may be explained by the contact 
of the plates hole surfaces with bolt threads, some little slippages on the grips and the deformation of plates. In other hand, in the numerical model the instant when the load increases again corresponds to a displacement of about $4 \mathrm{~mm}$ due only to the deformation of plates because the connection between grips and specimens is perfectly rigid and the bolt shank was modelled using the nominal diameter. Secondly, it is noted that there are two peak loads related to sliding of middle plates in relation to cover plates. This behaviour is due to inexistence of symmetry of specimen in both sides, inducing slippages in different testing time. These slippages in different testing time also occurred in slip tests. Inversely, the numerical model was only modelled $1 / 4$ of specimen and because for that simplification; it only appears one peak load in numerical load-displacement curve.

\begin{tabular}{|c|c|c|c|c|c|c|c|c|c|}
\hline \multirow{3}{*}{$\begin{array}{c}\text { Steel Grade } \\
\text { (Surface Treatment) }\end{array}$} & \multirow{3}{*}{ Type of Joint } & \multicolumn{4}{|c|}{ Snug Tight Bolts } & \multicolumn{4}{|c|}{ Preloaded Bolts } \\
\hline & & \multicolumn{2}{|c|}{$2 \mathrm{~mm}$ thick } & \multicolumn{2}{|c|}{$3 \mathrm{~mm}$ thick } & \multicolumn{2}{|c|}{$2 \mathrm{~mm}$ thick } & \multicolumn{2}{|c|}{$3 \mathrm{~mm}$ thick } \\
\hline & & $1+1$ & $4+4$ & $1+1$ & $4+4$ & $1+1$ & $4+4$ & $1+1$ & $4+4$ \\
\hline \multirow{4}{*}{$\begin{array}{c}\text { S355MC } \\
\text { (Without coating) }\end{array}$} & $F_{\max } \operatorname{Exp}_{0}$ & 36.69 & 100.57 & 59.18 & 153.45 & 39.03 & 105.10 & 63.05 & 161.66 \\
\hline & $\operatorname{CoV}(\%)$ & 1.71 & 0.80 & 0.42 & 0.86 & 1.64 & 5.42 & 1.91 & 0.46 \\
\hline & $F_{\max } F E M$ & 37.48 & 101.88 & 59.75 & 153.45 & 38.22 & 102.21 & 57.72 & 153.87 \\
\hline & Error $(\%)$ & -2.17 & -1.32 & -0.99 & 0.35 & 2.05 & 2.73 & 8.42 & 4.80 \\
\hline \multirow{4}{*}{$\begin{array}{c}\text { 350GD } \\
\text { (Zinc coating) }\end{array}$} & $F_{\max }$ Exp. & 39.81 & 101.18 & 55.16 & 150.77 & 42.84 & 110.37 & 56.28 & 141.71 \\
\hline & $\operatorname{CoV}(\%)$ & 1.38 & 1.55 & 1.15 & 0.24 & 3.83 & 5.08 & 5.46 & 2.11 \\
\hline & $F_{\max }$ FEM & 37.65 & 100.11 & 56.36 & 150.77 & 39.18 & 100.77 & 57.39 & 152.16 \\
\hline & Error (\%) & 5.40 & 1.03 & -2.21 & -5.58 & 8.53 & 8.68 & -2.00 & -7.40 \\
\hline \multirow{4}{*}{$\begin{array}{c}350 \mathrm{GD} \\
\text { (Zinc plus paint coating) }\end{array}$} & $F_{\max } \operatorname{Exp}$ & 37.96 & 100.18 & 52.09 & 139.17 & 39.85 & 99.91 & 55.45 & 140.35 \\
\hline & $\mathrm{CoV}(\%)$ & 2.05 & 0.73 & 0.87 & 1.48 & 0.92 & 1.24 & 0.85 & 1.46 \\
\hline & $F_{\max } F E M$ & 35.32 & 99.76 & 53.18 & 149.87 & 36.73 & 100.05 & 54.33 & 150.65 \\
\hline & Error (\%) & 6.95 & 0.39 & -2.14 & -7.72 & 7.79 & -0.16 & 1.99 & -7.37 \\
\hline
\end{tabular}

Table 6: Summary of failure loads in $\mathrm{kN}$ : experimental values, $F_{\max }$ Exp (first row) vs. numerical predictions, $F_{\max } F E M$, (third row). Coefficient of variation from three tests performed for each surface treatment (second row), and errors between average experimental failure loads and failure loads by FEM (fourth row).

As regards failure modes, Fig. 8 compares four distinct cases that were observed and modelled for $1+1$ and $4+4$ bolted joints. Fig. 8 shows that the numerical model can predict the failure location, as given by the equivalent plastic strain fields. Nevertheless, the numerical model does not use any damage approach (only plasticity), therefore it does not model the final cracking observed in experiments. The plasticity model predicts a plastic strain localization that results in strength reduction even before the final cracking. For the multiple bolted joints, this plastic strain localization is revealed with a more evident necking aspect. From Fig 8A and B (1+1 bolted joints) one verifies that the failure modes occurring on specimen of S355MC is by shear fracture; for specimen of S350GD steel the failure modes is a combination of shear and end splitting fracture. Regarding to $4+4$ bolted joints, it is verified the same failure mode, where the crack begins between the first two holes. In addition, it was also verified that the bolts closer to end of the cover plate are more subjected to loading than the bolts near the symmetry plane. Fig. 8 also shows necking on net-section for the $4+4$ bolted joints. From strain plots, one verifies that the numerical models can be appropriate to model the ultimate loads, reproducing local plastic strain fields similar to experimental results, being consistent with the critical points where the crack normally begins. Similar predictions of the failure models for bolted joints with thin plates were also obtained by He and Wang [15] using exclusively a plasticity model. This result was also validated by some of the authors of this paper in a previous publication [1].

In order to stablish a relationship between the geometry of single and multiple bolted connections and their fracture mode, the ratio between hole distances and hole diameter was calculated and compared with the definition of the bearing resistance proposed by Može and Beg [16]. Može and Beg refer that in case of single connections, if the member end distance is smaller than 2.5 times the $D_{\text {bole }}$, the lower bound of the bearing resistance is usually represented by splitting 
failure. However, if the edge distance, $e_{2}$, is lower than the end distance, $e_{1}$, the failure occurs mainly on the net crosssection, or if the edge distance is greater, the failure occurs by shear. Tab. 7 shows the ratios obtained from geometry data of specimens, verifying an average of $e_{1} / D_{\text {bole }}$ and $e_{2}$ sup $/ D_{\text {bole }}$ of 1.93 and 2.22 , respectively. For these ratios, specimens made of S355MC steel grade showed failure by shear and the S350GD exhibited failure by splitting and shear (Fig. 8 A

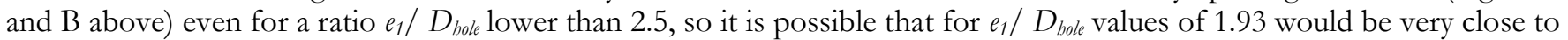
the lower bound of the bearing resistance. As regards to multiple bolted connections, the failure occurs on net crosssection for $e_{2}$ inf $/ D_{\text {bole }}$ equal to $e_{2}$ sup $/ D_{\text {bole }}$ and lower than $2.5, p_{2} / D_{\text {bole }}$ equal to 2.80 and $p_{1} / D_{\text {bole }}$ equal to 2.79 . Taking into consideration that the crack began between two holes it is possible that the ratio $p_{2} / D_{\text {bole }}$ will be very important for this type of failure.
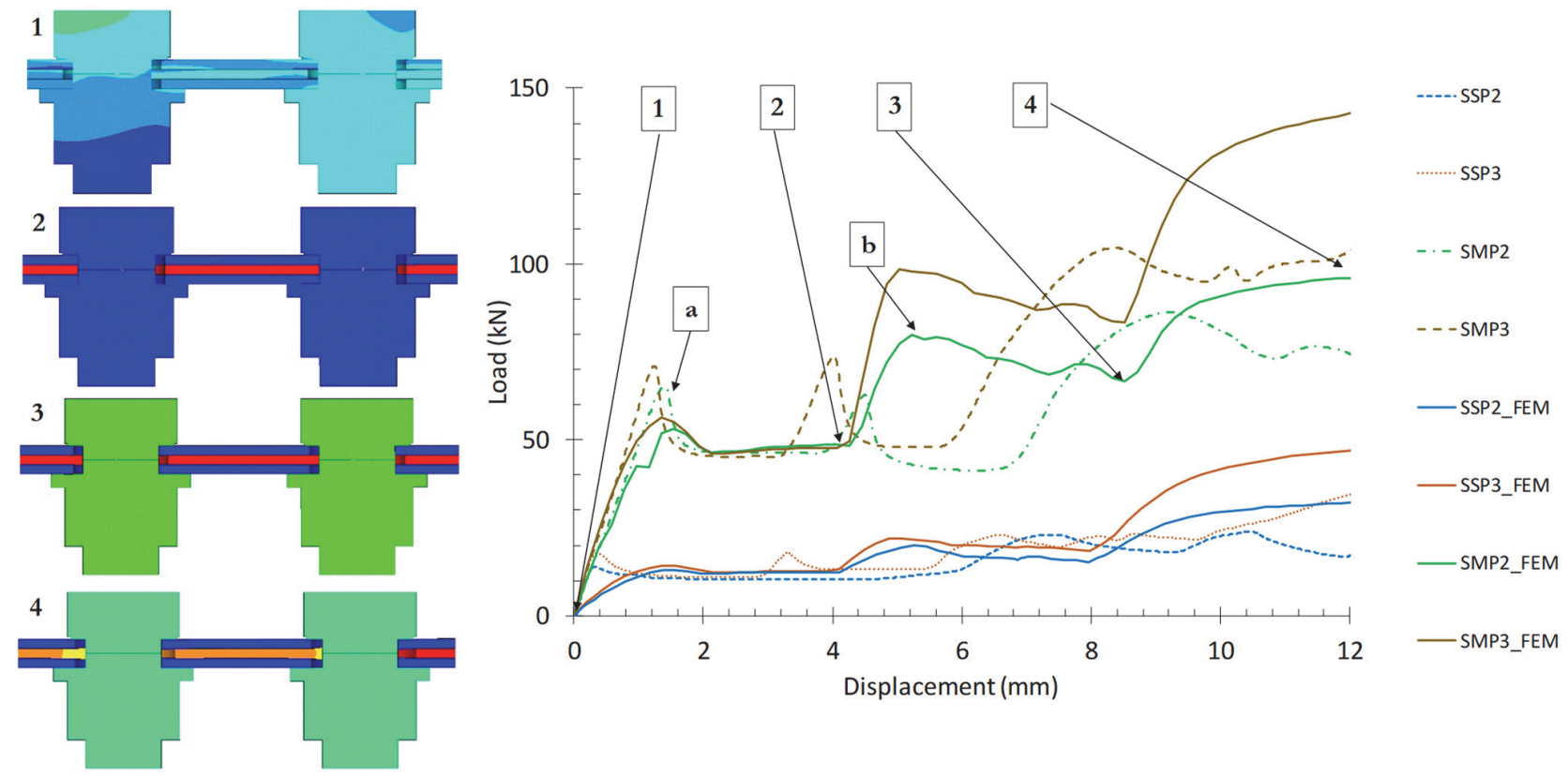

Figure 7: Experimental vs. numerical load-displacement curves for specimens made of S350GD and with zinc coating plus painting; preload level applied $70 \% \mathrm{Fu}$ or $560 \mathrm{MPa}$.
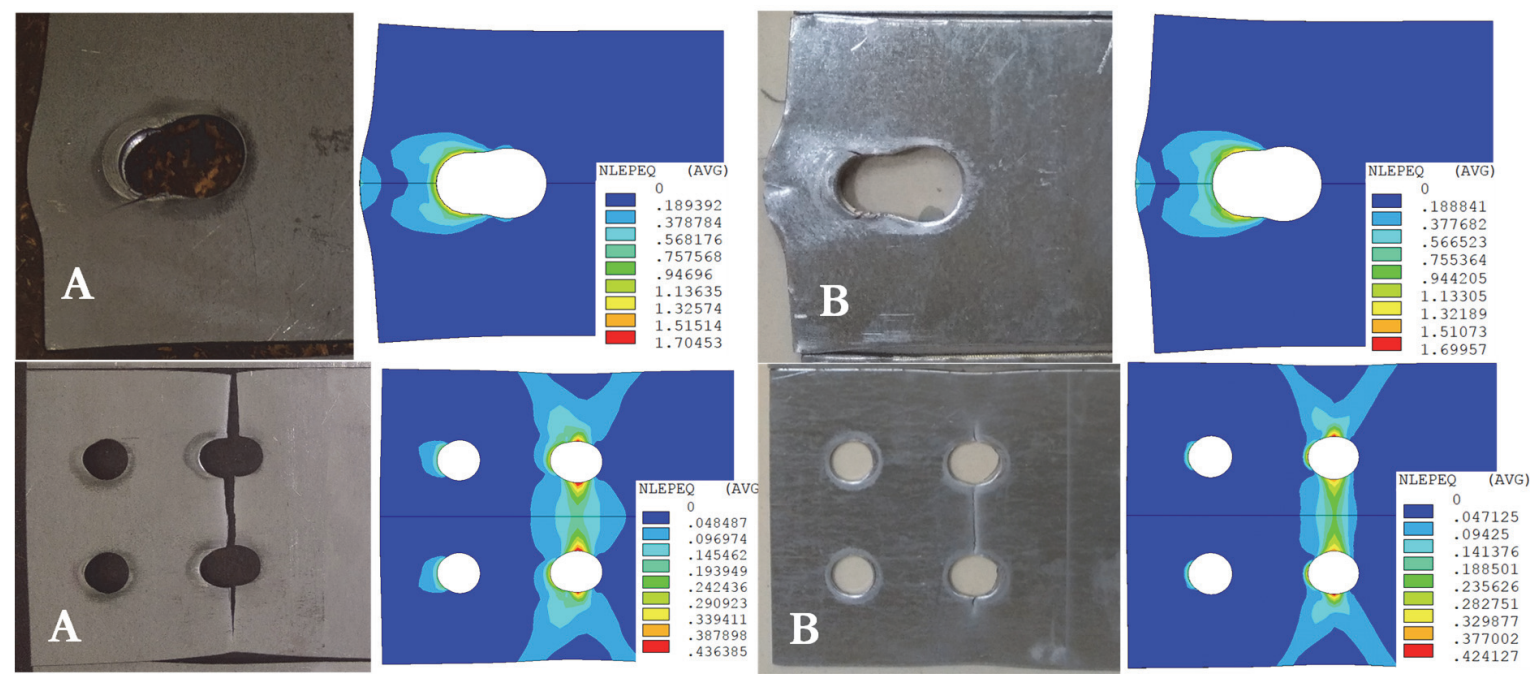

Figure 8: Experimental vs. numerical (equivalent plastic strain fields at ultimate loads) failure modes: above, $1+1$ bolted joints; below, 4+4 bolted joints (A-S355MC, B- S350GD). 


\begin{tabular}{cccccc}
\hline Specimen Series & $e_{1} / D_{\text {bole }}$ & $e_{2 \text { sup }} / D_{\text {hole }}$ & $e_{2}$ inf $/ D_{\text {hole }}$ & $p_{1} / D_{\text {bole }}$ & $p_{2} / D_{\text {hole }}$ \\
SSC2 & 1.94 & 2.22 & - & - & - \\
SSC3 & 1.94 & 2.22 & - & - & - \\
SSZ2 & 1.94 & 2.22 & - & - & - \\
SSZ3 & 1.92 & 2.23 & - & - & - \\
SSP2 & 1.94 & 2.23 & - & - & - \\
SSP3 & 1.91 & 2.22 & - & - & - \\
Average & $\mathbf{1 . 9 3}$ & $\mathbf{2 . 2 2}$ & - & - & - \\
\hline SMC2 & 1.95 & 2.24 & 2.24 & 2.79 & 2.80 \\
SMC3 & 1.95 & 2.24 & 2.24 & 2.80 & 2.80 \\
SMZ2 & 1.96 & 2.24 & 2.23 & 2.78 & 2.80 \\
SMZ3 & 1.96 & 2.25 & 2.24 & 2.79 & 2.80 \\
SMP2 & 1.96 & 2.25 & 2.24 & 2.78 & 2.79 \\
SMP3 & 1.95 & 2.25 & 2.25 & 2.78 & 2.79 \\
Average & $\mathbf{1 . 9 6}$ & $\mathbf{2 . 2 4}$ & $\mathbf{2 . 2 4}$ & $\mathbf{2 . 7 9}$ & $\mathbf{2 . 8 0}$ \\
\hline
\end{tabular}

Table 7: Geometric ratios between hole distances and hole diameter for single and multiple bolted connections.

\section{CONCLUSIONS}

$\mathrm{T}$

he purpose of this research was to evaluate the bolted connections behaviour including ductility, strength and slip factors. Firstly, it was verified a high variation on slip factors (slip tests) for each test performed with a maximum coefficient of variation value of $21.65 \%$. The slip tests revealed the lowest slip factor for the painted specimens, followed by the uncoated specimens, and the higher slip factor was verified for the zinc coated specimens. The comparison of the friction coefficients obtained with the slip and static tests showed significant deviations that may be partially justified by deviations in the coating processes including the coating thicknesses. The slip factors evaluated according to the EN 1090-2 standard should be preferable instead of using the static monotonic tests, since the first tests produced results that are more conservative.

The static/monotonic tests showed that the increase of thickness increases significantly the failure load and that high preloads increases the sliding loads. However higher preloads have not much influence on failure modes. In addition, it was possible to verify that the $4+4$ bolted joints are stiffer than $1+1$ bolted joints but reversely the limit displacements of single bolted connections are greater than observed for multiple bolted connections. The experimental results showed a higher coefficient of variation on ultimate loads for specimens with preloaded bolts. Performed numerical simulations allowed understanding that for low preload levels, the friction coefficient value is not very significant, but it may have important influence for high preloads and low thicknesses. For these reasons, the friction behaviour law should be properly modelled, taken into account the objectives and accuracy desired. The numerical results were very satisfactory with a maximum error of $8.7 \%$ in the ultimate loads estimation. Finally, from numerical simulations was possible to predict the failure location and ultimate loads without the use of a damage model, but only from detection of the peak load which occurs due the necking. Single bolted connection specimens without coating (355MC steel grade) showed only shear fracture, however single bolted connection specimens with zinc coating or zinc plus paint coating (350GD steel grade) showed two possibilities, shear and/or splitting fractures. As regards to multiple bolts connection, it was only verified fracture through net cross-section.

\section{ACKNOWLEDGMENTS}

$\mathrm{T}$

he authors express their gratitude to the FASTCOLD RFCS European Project (Grant Agreement No. 745982). Shelter S.A (Prokopis Tsintzos and Markos Mezari) is particularly acknowledged for the material supply. The SciTech (Science and Technology for Competitive and Sustainable Industries) R\&D project NORTE-01-0145- 
FEDER-000022 co-financed by Programme Operational Regional do Norte ("NORTE2020") through Fundo Europeu de Desenvolvimento Regional (FEDER) and the Portuguese Science Foundation (FCT) through the post-doctoral grant SFRH/BPD/107825/2015 are also acknowledged for their financial.

\section{REFERENCES}

[1] Rodrigues, M.F., Correia, J., Pedrosa, B., De Jesus, A., Carvalho, B., Rebelo, C., Xavier, J., Calçada, R. (2017). Numerical Analysis of a Double Shear Standard Bolted Connection Considering Monotonic Loadings, Eng. Struct. Technol., 9(4), pp. 183-194, DOI: 10.3846/2029882X.2017.1414638.

[2] Cruz, A., Simões, R., Alves, R. (2012). Slip factor in slip resistant joints with high strength steel, J. Constr. Steel Res., 70, pp. 280-288, DOI: 10.1016/j.jcsr.2011.11.001.

[3] Chung, K.F., Ip, K.H. (2001). Finite element investigation on the structural behaviour of cold-formed steel bolted connections, Eng. Struct., 23(9), pp. 1115-1125, DOI: 10.1016/S0141-0296(01)00006-2.

[4] Može, P. (2018). Bearing strength at bolt holes in connections with large end distance and bolt pitch, J. Constr. Steel Res., 147, pp. 132-144, DOI: 10.1016/j.jcsr.2018.04.006.

[5] Silva, J. (2009). Comparison between the Fatigue Behaviour of Riveted and Bolted Connections: MSc. Thesis. University of Trás-os-Montes and Alto Douro, Vila Real, Portugal, 249 (in Portuguese).

[6] De Jesus A.M.P., Silva A.L.L., Correia J.A.F.O. (2015). Fatigue of riveted and bolted joints made of puddle iron - An experimental approach. Journal of Constructional Steel Research 104, pp. 81-90.

[7] De Jesus A.M.P., Silva A.L.L., Correia J.A.F.O. (2014). Fatigue of riveted and bolted joints made of puddle iron - A numerical approach. Journal of Constructional Steel Research, 102, pp. 164-177

[8] CEN (European Committee for Standardization). (2008). EN 1090: Execution of steel structures and aluminium structures - Part 2: Technical requirements for the execution of steel structures, Brussels.

[9] Montgomery, J. (2008). Boundary condition influences on shank stress in 3D solid bolt simulation, in Conference proceedings 2008 Abaqus Users' Conference, May 19-22, Newport, Rhode Island, USA, 18.

[10] Kim, J.; Yoon, J.; Kang, B. (2006). Finite element analysis and modeling of structure with bolted joints, Applied Mathematical Modelling 31(5): 895-911. DOI: 10.1016/j.apm.2006.03.020.

[11]Zhang, G. (2013). Study on Computing Method in a Joint Fastener with Bolts, Inf. Technol. J., 12(13), pp. 25472553. DOI: $10.3923 /$ itj.2013.2547.2553

[12] Yun, X., Gardner, L. (2017). Stress-strain curves for hot-rolled steels, J. Constr. Steel Res., 133 , pp. 36-46. DOI: $10.1016 / j . j \operatorname{csr} .2017 .01 .024$.

[13] Gardner, L., Yun, X. (2018). Description of stress-strain curves for cold-formed steels, Constr. Build. Mater., 189, pp. 527-538, DOI: 10.1016/j.conbuildmat.2018.08.195.

[14] Picard, A. (1988). Guide to design criteria for bolted and riveted joints, Can. J. Civ. Eng., 15(1), pp. $142-143$. DOI: $10.1139 / 188-018$.

[15] He, Y.C., Wang, Y.C. (2011). Load-deflection behaviour of thin-walled plates with a single bolt in shearing, ThinWalled Struct., 49(10), pp. 1261-1276. DOI: 10.1016/j.tws.2011.05.008.

[16] Može, P., Beg, D. (2014). A complete study of bearing stress in single bolt connections, J. Constr. Steel Res., 95, pp. 126-140. DOI: 10.1016/j.jcsr.2013.12.002. 